\title{
Resolução de problemas matemáticos no "sexto ano" do ensino fundamental no município de Canoas
}

\author{
Solving mathematical problems in the "sixth year" of primary education in the \\ municipality of Canoas
}

\author{
Ancilla Dall'Onder Zat \\ claudiag1959@yahoo.com.br \\ Claudia Lisete Oliveira Groenwald \\ claudiag@ulbra.br
}

\begin{abstract}
Resumo
O presente artigo descreve uma atividade desenvolvida com um grupo de professores de Matemática do "sexto ano" do Ensino Fundamental que interagem, sob a orientação da Universidade, através de seus docentes pesquisadores, em integração com a Secretaria Municipal de Canoas/RS. O objetivo do estudo foi analisar como os alunos solucionam problemas matemáticos, envolvendo operações com Números Naturais e se existe uma base comum no desempenho destes alunos. Para a realização desta pesquisa, foram selecionados, resolvidos e aplicados dez problemas matemáticos, a cento e cinquenta alunos do sexto ano do Ensino Fundamental em seis turmas de quatro escolas municipais. A análise quantitativa e qualitativa dos resultados aponta perspectivas de base comum no desempenho dos alunos, salientando o papel do conhecimento matemático e das circunstâncias didático/pedagógicas que envolvem a solução de problemas como competências e habilidades.

Palavras-chave: Ensino fundamental; Resolução de problemas matemáticos; Sexto ano; Competências e habilidades.
\end{abstract}

\begin{abstract}
The article describes a developed activity with a Mathematics teachers' group of "year six" of Elementary Education who interact under the University guidance through their researcher docents, in integration with the Municipal Secretary of Canoas/RS. The objective of this study was to analyse how students solve mathematical problems, involving operations with natural numbers and wether there is a common base in these students' performance. To carry out this research, ten mathematical problems were selected, solved and applied to one hundred and fifty students of year six of Elementary Education in six classes of four municipal schools. The results' quantitative and qualitative analysis point to common base perspectives in the students performances, highlight the role of mathematical knowledge and the didactic/pedagogical circumstances that involve problem solving such as competences and abilities.
\end{abstract}

Keywords: Elementary education; Mathematics problem solving; Year six; Competences and abilities.

\section{Introdução}

Resolver problemas faz parte do cotidiano humano, sejam eles matemáticos ou não. $\mathrm{O}$ fundamental é que o mesmo seja um desafio, estimule o pensar, o levantar hipóteses, o experimentar e a verificação da solução encontrada. Um problema matemático requer do estudante algo mais que a habilidade de calcular, exige a compreensão do contexto, supõe conhecimentos prévios e que o aluno assuma o desafio da busca de uma solução.

Questiona-se, neste artigo, como os alunos do sexto ano do Ensino Fundamental solucionam problemas matemáticos, envolvendo operações com Números Naturais e, se 
existe perspectiva de uma base comum no desempenho desses estudantes. O estudo do tema torna-se relevante pelas circunstâncias que envolvem os alunos desse ano escolar, pelo fazer didático dos professores no ensino/aprendizagem, pelas perspectivas de aprimoramento profissional docente e pelas relações convergentes Escola/Secretaria Municipal de Educação/Universidade.

Os participantes de um grupo em formação continuada de professores municipais de Canoas/RS propuseram-se a ações de identificação, análise, resolução e aplicação, aos seus alunos, de problemas matemáticos, envolvendo as operações com Números Naturais, leitura e interpretação/representação de gráficos. A escolha e análise dos problemas que seriam adequados ao currículo do $6^{\circ}$ ano do Ensino Fundamental e as habilidades que os estudantes desse nível de ensino deveriam possuir para a resolução das atividades foi resultado do trabalho de um grupo de formação continuada composto por 8 professores de Matemática, da representante da área de Matemática do Município de Canoas e dois professores da Universidade Luterana do Brasil que se reuniram mensalmente no ano letivo de 2015.

\section{Problemas: um desafio ao aprender}

Ao longo dos tempos, a humanidade enfrentou dificuldades e buscou estratégias para superá-las. Carvalho (2010, p. 13) aponta que “A história da matemática foi e está sendo construída com resolução de problemas, porque, se o homem não tivesse um problema para resolver, ele não iria pensar em uma solução". Cotidianamente, surgem problemas que desafiam o pensar para solucioná-los. Mas o que é realmente um problema?

Para Dante (1989, p. 9-10), "É qualquer situação que exija o pensar do indivíduo para solucioná-la". Já o problema matemático, para o mesmo autor, "É qualquer situação que exija a maneira matemática de pensar e conhecimentos matemáticos para solucioná-la”.

Percebe-se que a forma de expressar o problema matemático afasta a ideia de atividade de rotina, indicando algo que pode ser feito mediante a ação do pensamento (SANCHEZ HUETE; FERNÁNDEZ BRAVO, 2006). Nesse sentido, Vila e Callejo (2006, p. 10) consideram que um problema “... não é simplesmente uma tarefa matemática, mas uma ferramenta para pensar matematicamente um meio para criar um ambiente de aprendizagem que forme sujeitos autônomos, críticos e propositivos...”.

Segundo Groenwald (2014, p. 2), um problema "é toda situação que se apresenta a um aluno, ou a um grupo de alunos, com conhecimentos suficientes para entendê-lo, mas que necessitam desenvolver um plano de ação para resolvê-lo". 
Endossam-se os conceitos, entendendo que um problema matemático é um mobilizador do pensamento que estabelece relações entre o saber, o fazer e o sentir na busca de uma solução criativa e possível.

Para Corso e Menza (1999, p. 113), resolver um problema matemático "implica o uso de técnicas, habilidades, estratégias e atitudes próprias de cada sujeito", pois consideram que solucionar um problema "não é repetir um procedimento, é um processo que implica tomar decisões, e a possibilidade de conhecer diretamente as consequências dessas decisões, a fim de modificá-las se for necessário, para adequá-las ao alcance do objetivo perseguido" (CORSO; MENZA, 1999, p. 112).

Existem diferentes propostas e pesquisas que abordam a resolução de problemas. Entretanto, observa-se a sua complexidade pelo envolvimento de muitas circunstâncias, como: conhecimento prévio, estágio de desenvolvimento do aluno - por exemplo, das operações concretas - fatores emocionais, socioeconômicos, didáticos, experiências anteriores, em suma, múltiplas variáveis intervêm no processo resolutório.

Villella (1998) chama atenção para o fato da resolução de problemas possibilitar o desenvolvimento de operações de pensamento (Quadro 1).

Quadro 1: Operações de pensamento

\begin{tabular}{|c|c|}
\hline OPERAÇÃO & CARACTERÍSTICAS \\
\hline Buscar suposições & $\begin{array}{l}\text { É estabelecer hipóteses, levando em consideração que elas podem ser verdadeiras } \\
\text { ou falsas. }\end{array}$ \\
\hline Classificar & $\begin{array}{l}\text { É agrupar conceitos, ideias, considerando certos atributos comuns, que devem ser } \\
\text { eleitos por quem realiza a tarefa. }\end{array}$ \\
\hline Codificar & $\begin{array}{l}\text { É transformar uma ideia em um elemento que pode dividir-se, o que implica } \\
\text { elaborar um quadro gráfico, linguístico, simbólico, possível de ser decodificado } \\
\text { pelo receptor da informação proposta. }\end{array}$ \\
\hline Comparar & $\begin{array}{l}\text { É observar diferenças e semelhanças para encontrar pontos de relação entre os } \\
\text { objetos e as ideias levadas em consideração. }\end{array}$ \\
\hline Planejar a ação & É traçar um plano de ação para solucionar uma situação conflituosa. \\
\hline Formular críticas & $\begin{array}{l}\text { É formular juízos, analisar e avaliar a situação, de acordo com certos princípios e } \\
\text { normas estabelecidas. }\end{array}$ \\
\hline Formular hipóteses & $\begin{array}{l}\text { É redigir um enunciado provisório, com caráter de tanteo, que se propõe com } \\
\text { possível solução de um problema. }\end{array}$ \\
\hline Imaginar & É formar uma ideia de algo não presente. \\
\hline Interpretar & É explicar o significado de uma situação estudada. \\
\hline Resumir & É estabelecer, e modo breve e condensado, a ideia do texto apresentado. \\
\hline Reunir e organizar dados & $\begin{array}{l}\text { É organizar os dados da situação estudada com o fim de utilizá-la para o } \\
\text { desenvolvimento das hipóteses, soluções... }\end{array}$ \\
\hline Tomar decisões & $\begin{array}{l}\text { É responder à pergunta: “que fazer e para quê?" envolvendo normas, leis e } \\
\text { procedimentos válidos, assim como valores que intervêm na situação a ser } \\
\text { resolvida. }\end{array}$ \\
\hline
\end{tabular}


Percebe-se que a resolução de problemas está associada a objetivos claros, que desafiam o aluno a refletir, estabelecer hipóteses, observar, comparar, organizar dados, aplicar conceitos e interpretar situações, entre outras operações que favoreçam a construção do conhecimento, ou seja, pensamento e ação estão integrados.

Entende-se que o problema matemático é um desafio que deve estar em consonância com o estágio de desenvolvimento do aluno, que desperte, por si só, o interesse e o desejo de compartilhá-lo com outras pessoas, que possibilite a aplicação de conhecimentos prévios e a elaboração de novos conhecimentos (CORSO; MENZA, 1999). Essa ideia é fortalecida por Sánchez Huete e Fernández Bravo (2006), acrescentando a essa adequação a formação integral, pois, ao resolver um problema, aprende-se algo novo.

A adoção de uma metodologia de resolução de problemas pressupõe a presença de algumas características básicas, como: a possibilidade de problematizar a situação; compreensão e atitude investigativa; ênfase no processo, delineando hipóteses; estabelecimento de relações e comparações entre o que se sabe e o que se está aprendendo; exercício do pensamento crítico na validação e expressão da possível solução. Acredita-se, portanto, que o processo didático na resolução de uma situação-problema vai além da formulação do desafio, da leitura, da compreensão do algoritmo, dos conteúdos e do significado dos vocábulos. Requer habilidades, raciocínio e atitudes, como comprometimento e persistência na busca de soluções (NCTM, 2014). Segundo o National Council of Teachers of Mathematics (NCTM, 2014), os estudantes devem ter experiências que lhes permitam, entre outras situações, construir socialmente o conhecimento, através do discurso, da atividade e da interação relacionadas com problemas significativos e desenvolver uma consciência metacognitiva de si mesmo como estudante, pensador e solucionador de problemas, aprendendo a supervisionar sua aprendizagem e desempenho.

Corso e Menza (1999) sugerem alguns passos metodológicos para a resolução de problemas: a correta leitura do enunciado do problema para que ações sejam condizentes com a sua solução; levantamento de hipóteses, delineamento do caminho e estratégias de intervenção docente em diferentes aspectos; releitura do enunciado do problema que permita a solução da hipótese mais adequada na busca da solução; validação através da revisão do que foi feito, individualmente ou em grupo.

$\mathrm{Na}$ perspectiva construtivista, as atividades de ensino e aprendizagem, em forma de desafios, contribuem para o desenvolvimento de habilidades como a observação, a leitura, a interpretação, a dedução e a postura crítica. 
Percebe-se que a solução de qualquer problema é um processo complexo que deve ser realizado, segundo Pólya (2006), seguindo uma série de passos determinados, apresentados a seguir:

a) Compreender o problema é a etapa de leitura do enunciado do problema, para identificar dados, incógnitas, determinar o que é pedido, que elementos se tem e quais fazem falta, que semelhanças e novidades há em relação a outra situação já vivenciada. As perguntas que podem facilitar são: Qual é a incógnita? Quais são os dados? Qual é a condição? A condição é suficiente para determinar a incógnita? É suficiente? Redundante? Contraditória?

b) Elaboração de um plano de ação é a etapa de criação de uma ou várias estratégias a seguir, para responder o que se pede. Refere-se à utilização de estratégias já conhecidas, provenientes de outros problemas resolvidos, uso de propriedades, simplificação do problema original em partes mais fáceis que ocupem menos tempo, determinação de tarefas e divisão de responsabilidades. As perguntas que podem facilitar são: Já encontrou um problema semelhante? Já viu o mesmo problema proposto de maneira um pouco diferente? Conhece um problema relacionado com esse? Conhece algum teorema que possa lhe ser útil? Esse é um problema relacionado com outro que já foi resolvido? Você poderia utilizá-lo? Poderia usar o seu resultado? Poderia empregar o seu método? Considera que seria necessário introduzir algum elemento auxiliar para poder utilizá-lo? Poderia enunciar o problema de outra forma? Poderia apresentá-lo de forma diferente novamente?

c) Executar o plano é a etapa em que se põe em prática o planejamento realizado, cumprindo ou não todas as fases, modificando aqueles elementos que representam obstáculos à solução do problema e comprovando ou refutando as hipóteses do plano, replanejando até encontrar a solução desejada.

d) Visão retrospectiva, avaliação do plano é a etapa do monitoramento da ação. Nela ressaltam-se dois aspectos: a avaliação da eficácia e eficiência do plano em função da comparação realizada com outros planos apresentados para resolver o mesmo problema; validação da solução encontrada, a qual se torna uma ferramenta para elaborar outras estratégias para utilização em problemas similares. As perguntas que podem facilitar são: Você pode verificar o resultado? Pode verificar o raciocínio? Pode obter o resultado de forma diferente? Pode vê-lo com apenas uma olhada? Você pode empregar o resultado ou o método em algum outro problema?

O professor deve motivar os alunos a reverem, durante a resolução de problemas, a forma de raciocínio utilizado, incentivando atitudes reflexivas quanto às diferentes maneiras 
de resolução, criando, assim, oportunidades para que os mesmos utilizem estratégias que exijam habilidades de construção de tabelas, de organização e interpretação de gráficos, entre outras. O professor deve, ainda, enfatizar a necessidade de testar cada mecanismo e forma de pensamento utilizado e intercalar, através da revisão ou da construção, os conteúdos matemáticos que porventura sejam necessários para a resolução.

Uma prática de solução de problemas, envolvendo os Números Naturais, permite observar indícios e discutir aspectos pertinentes, como a possibilidade de uma base curricular comum em todas as escolas. Também pode auxiliar os professores na escolha de situaçõesproblema que colaborem na superação das dificuldades dos estudantes e possibilitem revisitar conceitos que ainda necessitam de reforço.

\section{$O$ contexto da pesquisa}

A Lei $\mathrm{n}^{\mathrm{o}}$ 11.274, de 6 de fevereiro de 2006, ampliou de oito para nove anos o Ensino Fundamental, no Brasil, uma vez que a Lei $n^{0} 11.114 / 2005$ estendeu a obrigatoriedade do Ensino Fundamental a partir dos seis anos.

Nesse contexto, o aluno chega ou chegará ao sexto ano com um ano a mais de escolaridade, mas na mesma faixa etária entre 10 e 12 anos que teria na denominada $5^{\text {a }}$ série e, possivelmente, com os mesmos dilemas e preocupações. Convém acrescentar que, na teoria Piagetiana (1977), essa fase corresponde ao estágio das operações concretas, em transição para o estágio das operações formais.

Sabe-se que, até o $5^{\circ}$ ano escolar, é comum, com raras exceções, cada turma ter um único professor, o que de certa forma, por si só, garante certa continuidade no cotidiano da sala de aula. Mas, é no sexto ano que o aluno passa a ter um professor para cada componente curricular. Muitas vezes, esse estudante provém de outra escola, é também o momento em que ocorre um número significativo de reprovações em Matemática, requerendo do educador uma metodologia adequada ao contexto sociocultural do aluno, que lhe possibilite a interação com o objeto de conhecimento, pois, na aprendizagem, é importante o olhar atento do professor. Esse olhar expressa-se na identificação dos aspectos relevantes das situações de ensino a serem trabalhadas com seus estudantes, na utilização do conhecimento sobre o contexto das interações em sala de aula, e na realização de conexões entre o processo de ensino e aprendizagem que possibilitem tomar decisões de ação. Essas habilidades sintetizam o "observar com sentido", segundo Llinares (2012). Essa competência docente, vista como a inter-relação de três habilidades específicas (identificar, interpretar e tomar decisões de ação) 
torna a observação de uma sala de aula mais profissional, possibilitando ao professor a identificação de aspectos-chaves e a interpretação dos mesmos a partir de um referencial teórico existente.

\section{Metodologia da Pesquisa}

O presente estudo objetivou investigar o desempenho de estudantes do sexto ano do Ensino Fundamental, na solução de problemas com as operações básicas com Números Naturais. Com essa intenção, um grupo de professores de Matemática deste ano escolar discutiu o tema, participou da análise, seleção, resolução prévia e discussão de dez situaçõesproblema a serem aplicados aos seus alunos. O instrumento envolveu o conteúdo das operações básicas com Números Naturais, lógica, pensamento combinatório e tratamento da informação.

As atividades planejadas foram testadas previamente, em uma turma de "sexto ano", visando definir o grau de dificuldade das mesmas. A análise dos resultados do pré-teste apontou 3 questões fáceis, 4 questões de dificuldade média e 3 questões consideradas difíceis.

Entre as 10 atividades do instrumento aplicado foram consideradas fáceis as questões 1, 7 e 8, de dificuldade média, as questões 3, 4, 5 e 10, difíceis as questões 2, 6 e 9.

Nunes et al. (2012) define da seguinte forma os níveis de dificuldades: são consideradas fáceis as questões de aplicação direta de um conceito, uma propriedade ou um algoritmo. As questões de dificuldade média exigem leitura mais detalhada, interpretação e análise de dados, aplicando, na sua resolução, um ou mais conceitos. As questões difíceis necessitam de leitura, interpretação e análises mais detalhadas e elaboradas, exigindo elaboração de hipóteses, plano de ação e execução desse plano, na qual o estudante não conhece de imediato a resposta, necessita organizar o conhecimento já adquirido e adequá-lo na resolução da atividade (NUNES ET AL, 2012, p.1). Segundo Krulik e Reys (1997), as pesquisas consideram difíceis os problemas em que a estrutura da sentença é complexa ou quando contêm dados e/ou informações desconhecidas.

O instrumento foi aplicado pelos professores de Matemática participantes do grupo de formação continuada, em seis turmas de "sexto ano" do Ensino Fundamental, em quatro escolas do município de Canoas, do estado no Rio Grande do Sul, com o objetivo de analisarem as dificuldades e carências desses estudantes.

A análise e a discussão dos resultados focalizam o quantitativo, em percentuais, e o qualitativo, com os registros dos estudantes durante o desenvolvimento das atividades. 


\section{As atividades aplicadas no experimento}

Ao se constituírem como grupo, os professores de Matemática participantes do grupo de formação continuada delinearam atividades e ações que promovessem a reflexão e o pensar para o aperfeiçoamento da prática em sala de aula. Entre essas atividades/ações, foram realizadas: leituras de artigos relacionados ao projeto curricular (MACEDO, 2005) e a metodologia de problemas (GROENWALD, 2014; DUHALDE; CUBEREZ, 1998); reflexão sobre o currículo de Matemática do sexto ano e definição dos conteúdos que são trabalhados em sala de aula (pesquisados nos planos de ensino das escolas de atuação dos professores e nos livros didáticos adotados pelas escolas); as metodologias e os tipos de atividades que são adequadas a esse nível de ensino.

Concretizadas as ações iniciais, o grupo realizou diferentes atividades matemáticas que envolveram o pensar e o descobrir, com a finalidade de desenvolver o raciocínio dos alunos e a sinalização de formas adequadas de desencadear o processo de ensino e aprendizagem dos conteúdos matemáticos para esse nível escolar. A seguir, em continuidade, o grupo elaborou, resolveu e discutiu uma série de problemas matemáticos, envolvendo as quatro operações aritméticas com Números Naturais. Desses problemas, o grupo selecionou dez para serem aplicados aos seus alunos, assinalando as habilidades e competências requeridas à solução. Decidiram que seria muito importante conhecer o nível de conhecimentos dos estudantes e, para isso, optaram pela aplicação e análise das soluções dos problemas propostos.

O conteúdo abordado nas situações-problema caracterizou-se pelas quatro operações com Números Naturais, pelo conceito de cada operação, o significado dos termos envolvidos na operação, pensamento combinatório, leitura e interpretação de gráficos estatísticos, lógica e pela ideia de medida ou distância.

Entende-se como competência a "capacidade ou aptidão" (FERREIRA, 2008) para a realização de algo ou “... a capacidade que as pessoas desenvolvem de articular, relacionar saberes, conhecimentos, atitudes e valores, constituídos por intermédio de sua vivência e dos conhecimentos construídos na escola" (CRUZ, 2002, p. 29).

Le Boterf (1997 in PERRENOUD, 1999, p. 27) propõe "a ideia fundamental de mobilização, ao definir a competência como um saber-fazer" em determinada situação ou circunstância. Perrenoud (1999, p. 26) lembra que: “A partir do momento em que ele fizer - o que deve ser feito - sem sequer pensar, pois já o fez, não se fala mais em competência, mas sim em habilidades ou hábitos" que fazem parte da competência, segundo ele. 
Entende-se competência como a capacidade de mobilização de processos mentais para resolver problemas, ressaltando-se as habilidades que atuam em conjunto para o êxito da solução. Neste estudo, busca-se construir significados para os Números Naturais reconhecendo, no contexto social, diferentes significados, representações e operações necessárias à resolução de situações-problema envolvendo esse conjunto numérico.

As conceituações de competências e habilidades contribuíram para as definições expressas em cada atividade do instrumento de pesquisa, como se observa no quadro 2 .

Quadro 2: Problemas matemáticos para o $6^{\circ}$ ano do Ensino Fundamental

\begin{tabular}{|c|c|c|c|c|}
\hline Problema & Dificuldade & Conteúdo & Competências & Habilidades \\
\hline $\begin{array}{l}\text { 1. Uma biblioteca recebeu a doação de } 1422 \\
\text { livros, enquanto uma escola recebeu } 1392 \\
\text { livros. A escola recebeu quantos livros a } \\
\text { menos do que a biblioteca? (Dante, 2009) }\end{array}$ & Fácil & $\begin{array}{l}\text { Algoritmo da } \\
\text { subtração com } \\
\text { Números Naturais }\end{array}$ & $\begin{array}{l}\text { Leitura } \\
\text { interpretação }\end{array}$ & Cálculo \\
\hline $\begin{array}{l}\text { 2. Se Laura gastar a metade do que tem, ela } \\
\text { poderá comprar } 3 \text { CDs de } 18 \text { reais cada um. } \\
\text { A quantia que Laura tem é: } \\
\begin{array}{ll}\text { a) } 27 \text { reais } & \text { c) } 54 \text { reais } \\
\text { b) } 108 \text { reais } & \text { d) } 91 \text { reais } \\
\text { (Dante, 2009) } & \end{array}\end{array}$ & Difícil & $\begin{array}{l}\text { Conceito de } \\
\text { metade } \\
\text { algoritmo da } \\
\text { multiplicação com } \\
\text { Números Naturais }\end{array}$ & $\begin{array}{l}\text { Leitura e } \\
\text { interpretação } \\
\text { Inversão } \\
\text { (metade/ dobro) }\end{array}$ & $\begin{array}{l}\text { Compreensão do } \\
\text { conceito e cálculo }\end{array}$ \\
\hline $\begin{array}{l}\text { 3. Carmem tem três saias, preta, azul e } \\
\text { branca, e duas blusas, vermelha e amarela. } \\
\text { Quais combinações ela pode fazer? } \\
\text { (Carvalho, 2010). }\end{array}$ & Média & $\begin{array}{l}\text { Pensamento } \\
\text { combinatório }\end{array}$ & $\begin{array}{l}\text { Leitura } \\
\text { interpretação } \\
\text { Definição de } \\
\text { Hipóteses } \\
\end{array}$ & $\begin{array}{l}\text { Organização de } \\
\text { esquemas } \\
\text { Representação } \\
\text { por diagramas }\end{array}$ \\
\hline $\begin{array}{l}\text { 4. Tenho } 26 \text { balas para distribuir igualmente } \\
\text { entre } 4 \text { crianças. Quantas balas não serão } \\
\text { distribuídas? (Carvalho, 2010). }\end{array}$ & Média & $\begin{array}{l}\text { Algoritmo da } \\
\text { divisão, } \\
\text { subtração, resto, } \\
\text { com Números } \\
\text { Naturais } \\
\end{array}$ & $\begin{array}{ll}\text { Leitura } & \text { e } \\
\text { interpretação } & \\
\text { Relação entre } & \text { a } \\
\text { informação e } & \text { a } \\
\text { negação } & \\
\end{array}$ & $\begin{array}{l}\text { Cálculo e } \\
\text { compreensão dos } \\
\text { conceitos das } \\
\text { operações e do } \\
\text { resto da divisão }\end{array}$ \\
\hline $\begin{array}{l}\text { 5. Uma estrada tem } 189 \text { quilômetros. Um } \\
\text { caminhoneiro parou no quilômetro } 84 \text { para } \\
\text { abastecer. Quando estava no quilômetro 109, } \\
\text { o pneu furou. Quantos quilômetros o } \\
\text { caminhoneiro andou do momento que } \\
\text { abasteceu até a hora que o pneu furou? } \\
\text { (Carvalho, 2010). }\end{array}$ & Média & $\begin{array}{l}\text { Algoritmo da } \\
\text { subtração com } \\
\text { Números Naturais } \\
\text { e conceito de } \\
\text { medida }\end{array}$ & $\begin{array}{l}\text { Leitura e } \\
\text { interpretação } \\
\text { Percepção do } \\
\text { excesso de dados }\end{array}$ & $\begin{array}{l}\text { Cálculo e } \\
\text { compreensão dos } \\
\text { conceitos }\end{array}$ \\
\hline $\begin{array}{l}\text { 6. Pedro e João têm R\$ } 180,00 \text {. Sabendo que } \\
\text { Pedro tem R\$ } 110,00 \text {. De quanto a quantia de } \\
\text { Pedro excede a de João? (autoria própria). }\end{array}$ & Difícil & $\begin{array}{l}\text { Algoritmo da } \\
\text { subtração com } \\
\text { números naturais } \\
\text { e conceito de } \\
\text { excesso }\end{array}$ & $\begin{array}{l}\text { Leitura } \\
\text { interpretação } \\
\text { Análise }\end{array}$ & $\begin{array}{l}\text { Cálculo e } \\
\text { compreensão dos } \\
\text { conceitos }\end{array}$ \\
\hline $\begin{array}{l}\text { 7. Um mesmo modelo de telefone está sendo } \\
\text { vendido na Loja "Preço Bom" em } 4 \\
\text { prestações de } 19 \text { reais cada uma e na Loja } \\
\text { "Barateira" por } 78 \text { reais. Em qual das lojas o } \\
\text { preço do telefone é menor? (Dante, 2009). }\end{array}$ & Fácil & $\begin{array}{l}\text { Algoritmo da } \\
\text { multiplicação com } \\
\text { Números Naturais }\end{array}$ & $\begin{array}{l}\text { Leitura } \\
\text { intepretação } \\
\text { Comparação }\end{array}$ & Cálculo \\
\hline $\begin{array}{l}\text { 8. Juca ganhou } 15 \text { bombons de sua madrinha. } \\
7 \text { são bombons de cereja e o restante de } \\
\text { marzipã. Quantos bombons não são de } \\
\text { cereja? (Carvalho, 2010). }\end{array}$ & Fácil & $\begin{array}{l}\text { Algoritmo da } \\
\text { Subtração com } \\
\text { Números Naturais }\end{array}$ & $\begin{array}{ll}\text { Leitura } & \text { e } \\
\text { interpretação } & \\
\text { Relação entre } & \text { a } \\
\text { informação e } & \text { a } \\
\text { negação } & \end{array}$ & Cálculo \\
\hline $\begin{array}{l}\text { 9. As avós Antonieta, Altair, Jandira e Sônia } \\
\text { gostam muito de seus netos. Mas são avós } \\
\text { com idades muito diferentes. Elas têm } 96,48 \text {, } \\
68 \text { e } 51 \text { anos. Descubra as idades das avós de } \\
\text { Ricardo, Bruno, Gustavo e Wilson. } \\
\text { A avó do Gustavo é } 17 \text { anos mais velha } \\
\text { que a avó Sônia. }\end{array}$ & Difícil & Lógica & $\begin{array}{l}\text { Leitura } \\
\text { interpretação }\end{array}$ & $\begin{array}{l}\text { Organização de } \\
\text { esquemas } \\
\text { Representação } \\
\text { por gráficos }\end{array}$ \\
\hline
\end{tabular}




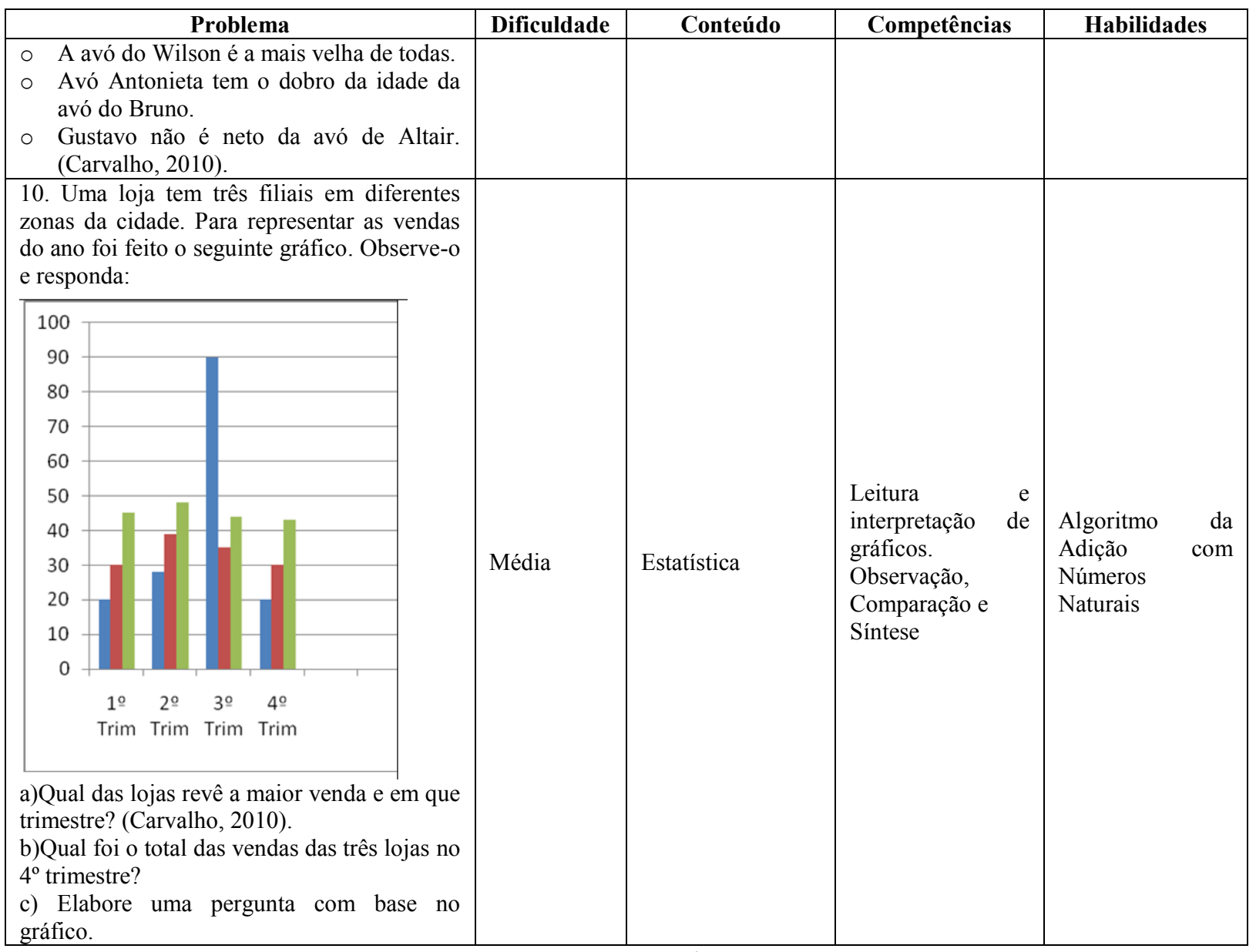

Fonte: A pesquisa.

$\mathrm{Na}$ resolução de problemas matemáticos, mobilizam-se processos mentais que requerem o saber (o conhecer), o fazer (as habilidades) e o assumir (atitudes) diante da situação desafiadora. Nesse sentido, as atividades selecionadas para aplicação em estudantes do sexto ano do Ensino Fundamental contemplam a leitura e interpretação da atividade, leitura e interpretação de gráficos, levantamento de hipóteses, percepção do excesso de dados, relação entre a informação e a negação, pensamento lógico, combinatório e o exercício da observação, análise e síntese. Para a concretização dessas competências, convém lembrar a necessidade das habilidades de cálculo das quatro operações básicas com Números Naturais, esquemas, diagramas e gráficos.

Em sequência, a atividade proposta foi aplicada em seis turmas do $6^{\circ}$ ano do Ensino Fundamental de quatro ${ }^{1}$ escolas municipais de Canoas. A análise dos resultados evidencia o desempenho dos participantes desta pesquisa.

\footnotetext{
${ }^{1}$ Duas eescolas aplicaram nas turmas A e B.
} 


\section{Problemas matemáticos: análise e discussão das resoluções}

A idade média dos alunos, sujeitos desta pesquisa foi de, aproximadamente, onze anos e sete meses, permitindo afirmar que se situam numa transição entre os estágios de desenvolvimento das operações concretas (Piaget, 1977) e o início do nível operatório abstrato. Em relação ao gênero, o grupo é constituído de setenta e oito meninos e setenta e duas meninas.

Em média, o número de alunos por turma era de vinte e cinco estudantes, com uma amplitude máxima de sete alunos. Considera-se a possibilidade de que o tamanho da turma seja padrão referencial para o ano escolar em estudo. A turma com maior número de alunos, no experimento realizado, apresentou o melhor desempenho na resolução das situaçõesproblema, contrariando as afirmativas de que turmas menores têm maior possibilidade de rendimento.

A análise do desempenho em relação à idade (Tabela 1) chama atenção pela correlação inversa entre idade e desempenho, o que parece ser coerente com as políticas que clamam pela "idade certa" desde a alfabetização.

Tabela 1: Perfil dos estudantes do $6^{\circ}$ ano escolar

\begin{tabular}{|c|c|c|c|c|c|}
\hline \multirow{2}{*}{ Escola } & \multicolumn{3}{|c|}{$\mathrm{N}^{\circ}$ de alunos } & \multirow{2}{*}{$\begin{array}{l}\text { Idade média } \\
\text { (em a. e me) }\end{array}$} & \multirow[t]{2}{*}{ Desempenho (média) } \\
\hline & $\mathrm{M}$ & $\mathrm{F}$ & $\mathrm{T}$ & & \\
\hline 1 & 16 & 8 & 24 & $11 \mathrm{a} 5 \mathrm{me}$ & 5,79 \\
\hline 2 & 12 & 17 & 29 & $11 \mathrm{a} 6 \mathrm{me}$ & $6,65^{2}$ \\
\hline $3 \mathrm{~A}$ & 13 & 11 & 24 & $11 \mathrm{a} 2 \mathrm{me}$ & 5,12 \\
\hline $3 B$ & 10 & 12 & 22 & $12 \mathrm{a} 4 \mathrm{me}$ & 4,68 \\
\hline $4 \mathrm{~A}$ & 11 & 14 & 25 & 11a $10 \mathrm{me}$ & 6,48 \\
\hline $4 \mathrm{~B}$ & 16 & 10 & 26 & $12 \mathrm{a} 4 \mathrm{me}$ & $3,80^{3}$ \\
\hline Total & 78 & 72 & 150 & $\sim 11 \mathrm{a} 7 \mathrm{me}$ & 5,46 \\
\hline
\end{tabular}

Constata-se, também, a presença de desempenho menos significativo, no experimento realizado, nas turmas $\mathrm{B}$, com estudantes que possuem média de idade acima de 12 anos.

Investigar as respostas dadas pelos alunos na solução de problemas é uma oportunidade rica em possibilidades de informações. A análise pode fornecer elementos indicativos em relação ao conteúdo específico do ano escolar, às estratégias adotadas, à contextualização das atividades e à formação didática do professor. Deduz-se que ao analisar a solução de problemas, sem estar em situação de avaliação, com conceito ou nota dada aos alunos, podem-se estudar suas respostas, sem objetivar o erro, mas, como indicação para o desenvolvimento de práticas pedagógicas e de competências e habilidades.

\footnotetext{
${ }^{2}$ Maior desempenho.

${ }^{3}$ Menor desempenho.
} 
Para Cury (2007, p. 62-63), “Um texto matemático produzido por um aluno [...] pode ser analisado com base em procedimentos sistemáticos para inferir conhecimentos sobre as formas com que aquele estudante construiu um determinado saber matemático". Nessa perspectiva, podem-se viabilizar processos didáticos que preencham lacunas no ensino/aprendizagem da solução de problemas com operações básicas com Números Naturais no sexto ano do Ensino Fundamental.

A Tabela 2 apresenta o desempenho analisado em cada questão e o desempenho das turmas participantes do experimento.

Tabela 2: Síntese do desempenho nos problemas matemáticos

\begin{tabular}{|c|c|c|c|c|c|c|c|c|c|c|c|c|c|}
\hline \multirow{2}{*}{$\begin{array}{c}\text { Escola } \\
\text { Municipal }\end{array}$} & \multirow{2}{*}{$\begin{array}{l}\mathrm{N}^{\circ} \text { de } \\
\text { alunos }\end{array}$} & \multicolumn{10}{|c|}{ Questões } & \multicolumn{2}{|c|}{ Total } \\
\hline & & 1 & 2 & 3 & 4 & 5 & 6 & 7 & 8 & 9 & 10 & $\mathrm{~N}^{\mathrm{o}}$ & $\%$ \\
\hline 1 & 24 & 19 & 10 & 9 & 16 & 19 & 10 & 16 & 21 & 7 & 12 & 139 & 57,9 \\
\hline 2 & 29 & 24 & 14 & 15 & 17 & 20 & 8 & 26 & 27 & 19 & 23 & 193 & 67,0 \\
\hline $3 \mathrm{~A}$ & 24 & 22 & 8 & 3 & 10 & 11 & 3 & 22 & 23 & 7 & 14 & 123 & 51,2 \\
\hline $3 B$ & 22 & 20 & 1 & 4 & 12 & 10 & 1 & 18 & 21 & 4 & 12 & 103 & 46,8 \\
\hline $4 \mathrm{~A}$ & 25 & 19 & 9 & 14 & 22 & 19 & 8 & 19 & 23 & 13 & 16 & 162 & 64,8 \\
\hline 4B & 26 & 23 & 1 & 5 & 10 & 7 & zero & 21 & 19 & 1 & 12 & 99 & 38,0 \\
\hline Total & 150 & 127 & 43 & 50 & 87 & 86 & 30 & 122 & 134 & 51 & 89 & 819 & - \\
\hline $\begin{array}{c}\text { Percentual de } \\
\text { acertos }(\%)\end{array}$ & 100 & 84 & 29 & 33 & 58 & 57 & 20 & 81 & 89 & 34 & 59 & - & - \\
\hline
\end{tabular}

Fonte: dados da pesquisa.

Observando-se o desempenho dos participantes em cada uma das situações (Tabela 2) evidenciam-se alguns aspectos que merecem uma análise mais particularizada. A primeira atividade, considerada fácil, envolve a operação de subtração e requer a habilidade de leitura e interpretação. Entretanto, para interpretar, há a necessidade de compreender não só a operação, mas o significado dos termos envolvidos no texto que descreve o contexto, como por exemplo, "a menos do que". Embora aproximadamente $85 \%$ dos alunos tenham respondido afirmativamente, seria conveniente enriquecer o vocabulário e/ou a busca do significado dos termos. Seria desejável (DUHALDE; CUBERES, 1998) que os alunos se perguntassem “o que significa”. Observa-se uma resolução correta na figura 1.

Figura 1: resolução correta do problema 1 por um estudante participante do experimento

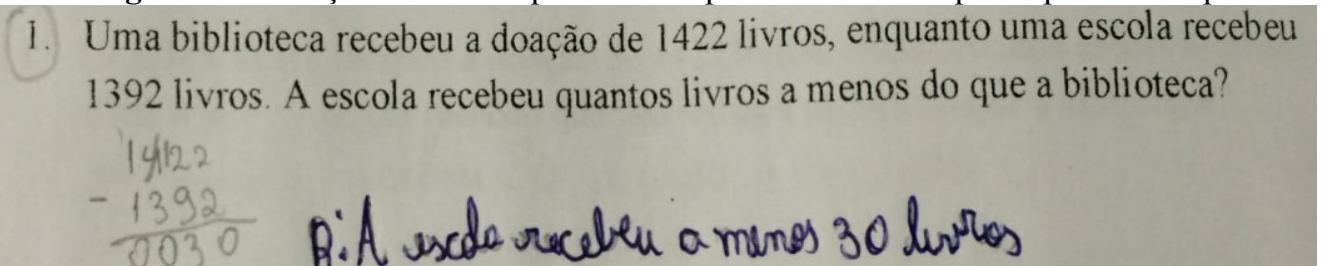

Fonte: dados da pesquisa.

As questões seis e oito apresentavam similaridade com a primeira situação-problema em relação à leitura, interpretação e habilidade no cálculo da operação de subtração, 
entretanto, na atividade seis, há a necessidade de exercer a análise de relações e compreensão do termo "excede". A Figura 2 apresenta uma resolução correta do problema 6.

Figura 2: resolução correta do problema 6 por um estudante participante do experimento

6. Pedro e João têm juntos R\$ 180,00. Sabendo que Pedro tem RS 110,00 , de quanto a quantia de Pedro excede a de João?

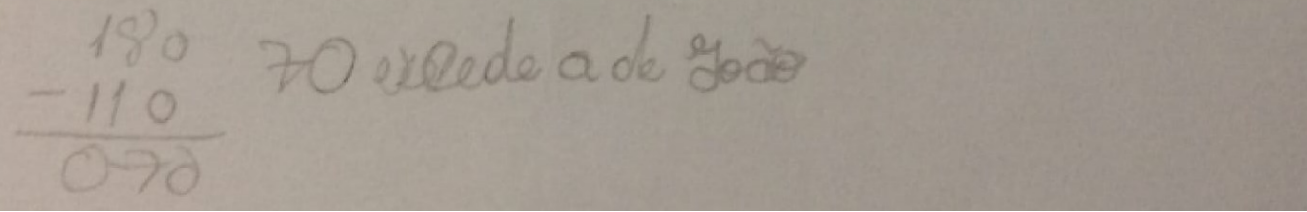

Fonte: dados da pesquisa.

A atividade oito, por sua vez, requer a relação entre a informação e a negação da pergunta, além do já citado. A resposta do aluno, na figura 3, demonstra que não houve a construção do conceito da operação (Questão 8).

Figura 3: resolução incorreta do problema 8 de um estudante participante do experimento

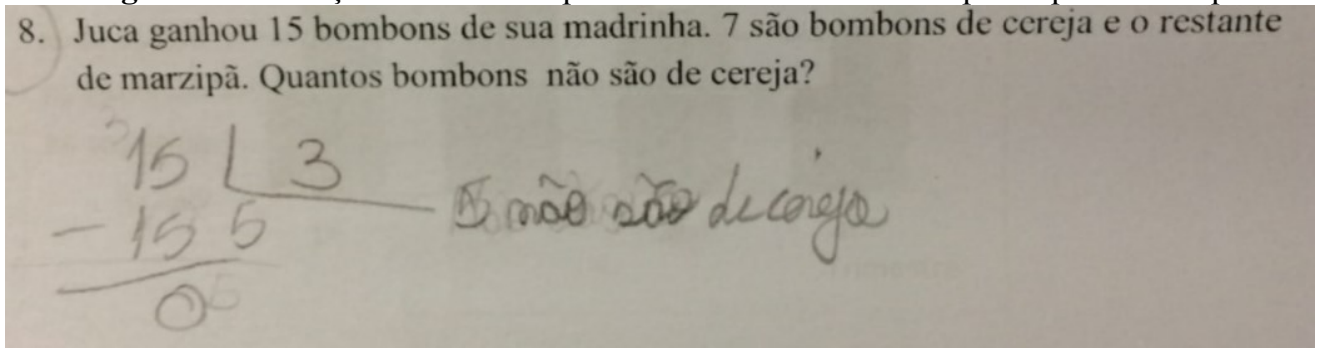

Fonte: dados da pesquisa.

A questão quatro também opera com a subtração, mas não é a única operação, pois envolve divisão, multiplicação, subtração e o significado de resto. Nas situações que envolvem divisão com resto, usualmente, a pergunta dirige seu foco para o quociente, entretanto, para Carvalho (2010, p. 41), “... também podem propiciar perguntas negativas”, como nesse caso. Afirma, ainda, a referida autora, que "esse tipo de problema possibilita ao aluno estabelecer relação entre a informação do problema e a negação da pergunta para solucioná-lo” (p. 41). Observa-se que o desempenho do grupo, nessa situação, apresenta um percentual positivo de cinquenta e oito por cento. Observa-se um exemplo na Figura 4, de uma resolução correta e resposta incorreta.

Figura 4: resolução incorreta do problema 4 por um estudante.

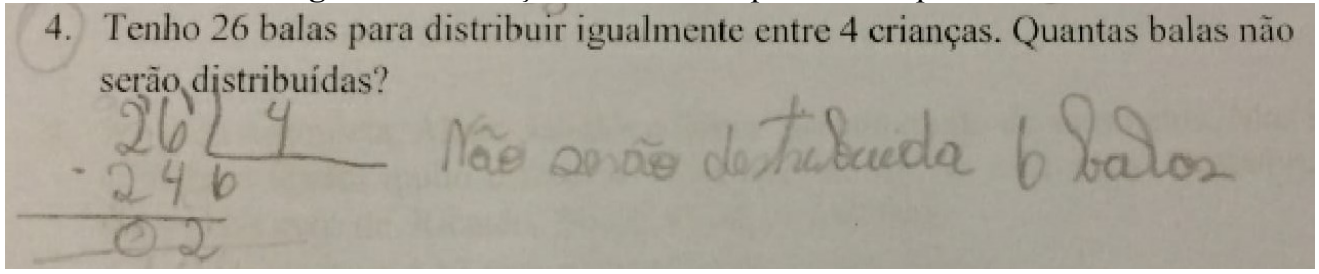

Fonte: dados da pesquisa. 
A atividade proposta, na questão cinco, também requer o cálculo da operação, subtração, envolvendo a ideia de medida, mas, para aplicar o cálculo, adequadamente, é necessária a leitura e interpretação na seleção dos dados, uma vez que lida com o excesso de informações. O grupo apresentou um desempenho positivo de cinquenta e sete por cento nessa atividade, cujo objetivo atende ao desenvolvimento da percepção das informações necessárias à solução e, portanto, necessita de atenção na leitura, seleção e interpretação das mesmas (exemplo na Figura 5).

Figura 5: resolução incorreta do problema 5 por um estudante participante do experimento

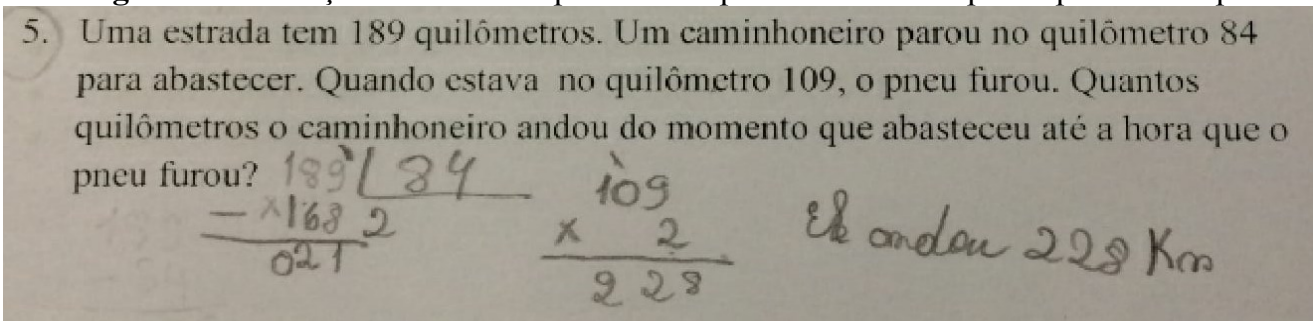

Fonte: dados da pesquisa.

O problema proposto na questão sete apresenta uma situação de familiaridade para os alunos, em virtude das múltiplas fontes de propaganda na mídia e pela atualidade do tema. Exige a operação de multiplicação, mas envolve a leitura e interpretação para efetuar a comparação. No caso, o termo "menor" remete à ideia de comparação positiva e terá que ser feita pela subtração, para calcular a diferença entre os preços. Apresenta um aproveitamento positivo de oitenta e um por cento das soluções, chamando a atenção para a atualidade da contextualização (exemplo na Figura 6).

Figura 6: resolução correta do problema 7 por um estudante participante do experimento.

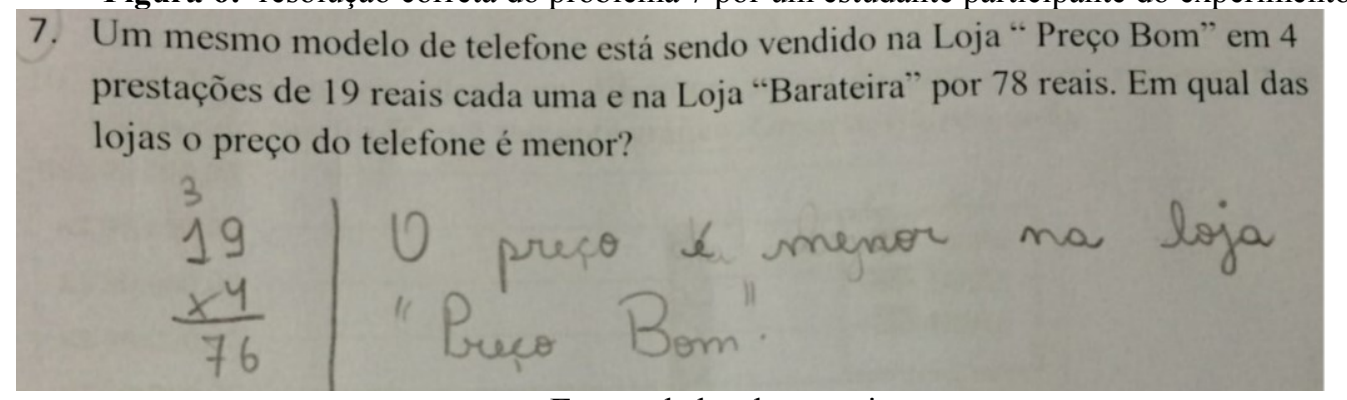

Fonte: dados da pesquisa.

A situação-problema de número dois oferece uma contextualização específica, remetendo à habilidade multiplicativa, após a leitura e interpretação, com o entendimento de inversão metade/dobro. Enquanto isso "a palavra dobro leva à operação de multiplicação..." (CARVALHO, 2010, p. 28). Mas, para resolver algum problema, utiliza-se a divisão. É evidente que, para metade, usar-se-á, nessas circunstâncias, a multiplicação. A questão também oferece a possibilidade de múltipla escolha e obteve um resultado de 
aproximadamente vinte e nove por cento de acertos, ficando aquém do desempenho desejado (exemplo resolvido corretamente na Figura 7).

Figura 7: problema 2 resolvido corretamente por um estudante participante do experimento

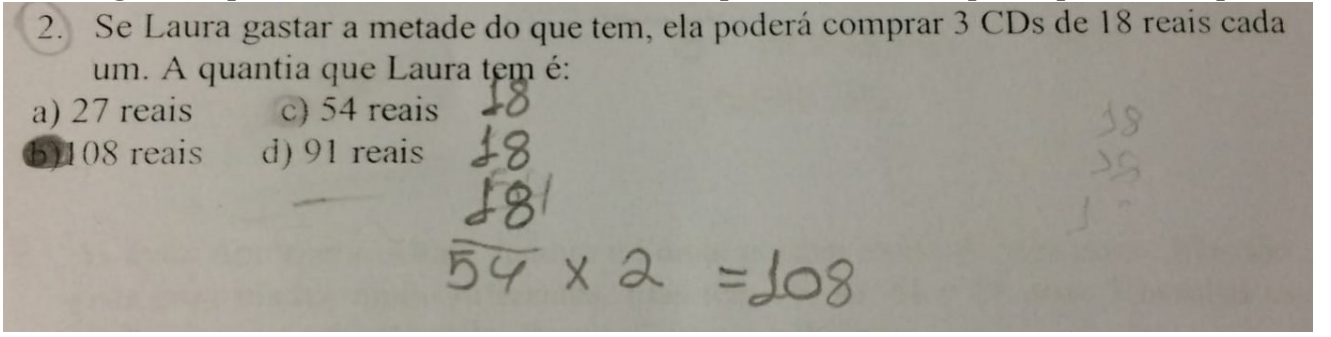

Fonte: dados da pesquisa.

Sabe-se que, em um enunciado, há um texto a ser lido, interpretado e informações e questionamentos para levantar hipóteses e traçar estratégias de resolução. Entretanto, existem palavras no vocabulário matemático que contribuem para melhor entender e relacionar a situação à operação, como por exemplo: somei, ganhei, perdi, adicionei, acumulei, retirei, dividi, metade, dobro, distribuí, resto, sobrou, repartiu, trocou, entre outras. Assim, a contribuição vocabular pode vir de outras fontes, além da Matemática.

A atividade de número três aborda o pensamento combinatório, exige leitura, interpretação e levantamento de hipótese. Sua solução remete a diferentes estratégias para resolvê-la, como diagramas e esquemas até a testagem das hipóteses. Evidenciou-se um desempenho grupal de apenas trinta e três por cento de efetividade, o que permite lembrar, segundo Goulart (1996, p. 117-118), que “A emergência do pensamento combinatório é uma característica do pensamento lógico formal e acontece por volta dos 11/12 a 14/15 anos. [...] Trata-se de simples tentativas empíricas, não sistemáticas, mas que já revelam progresso". Essas afirmações parecem justificar o desempenho obtido no experimento, uma vez que a faixa etária dos participantes desta pesquisa varia de 11 anos e 2 meses a 12 anos e 4 meses, apresenta-se um exemplo de uma resolução incorreta, na Figura 8, onde o estudante calcula corretamente mas não responde adequadamente, pois a pergunta do problema era quais combinações são possíveis.

Figura 8: resolução incorreta da atividade 3 por um estudante participante do experimento

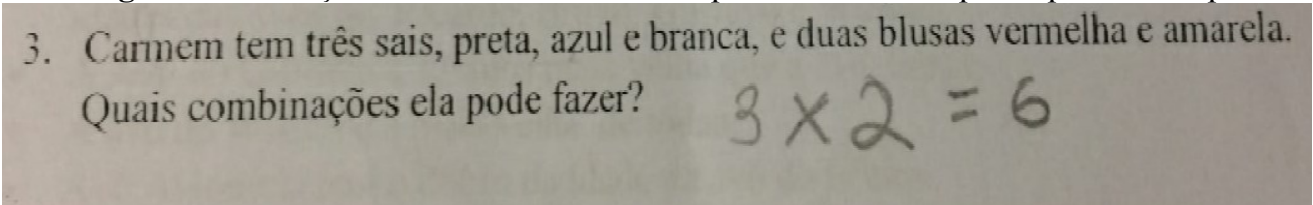

Fonte: dados da pesquisa.

Ao verificar os resultados da questão nove, constatou-se um percentual de trinta e quatro por cento de positividade. É um problema desafiador, como afirmou um dos 
respondentes: "tentei, mas não consegui". O problema envolve o pensamento lógico, a leitura e a interpretação. Sua solução pode ocorrer usando esquemas e gráficos. Pela teoria Piagetiana, quando a situação envolve diversas variáveis, o pensamento lógico se concretiza no final da fase operacional concreta (9 a 11 anos); entretanto, quando as variáveis são mais complexas, só será possível, na fase operacional formal, que parece ser este caso. Não significa que se deve evitar este tipo de desafio, mas recomenda-se prudência (KRULIK; REYS, 1997).

$\mathrm{Na}$ Figura 9, apresenta-se o exemplo da resolução correta por um estudante participante do experimento que utilizou um esquema gráfico para sua resolução.

Figura 9: resolução correta da atividade 9 por um estudante participante do experimento

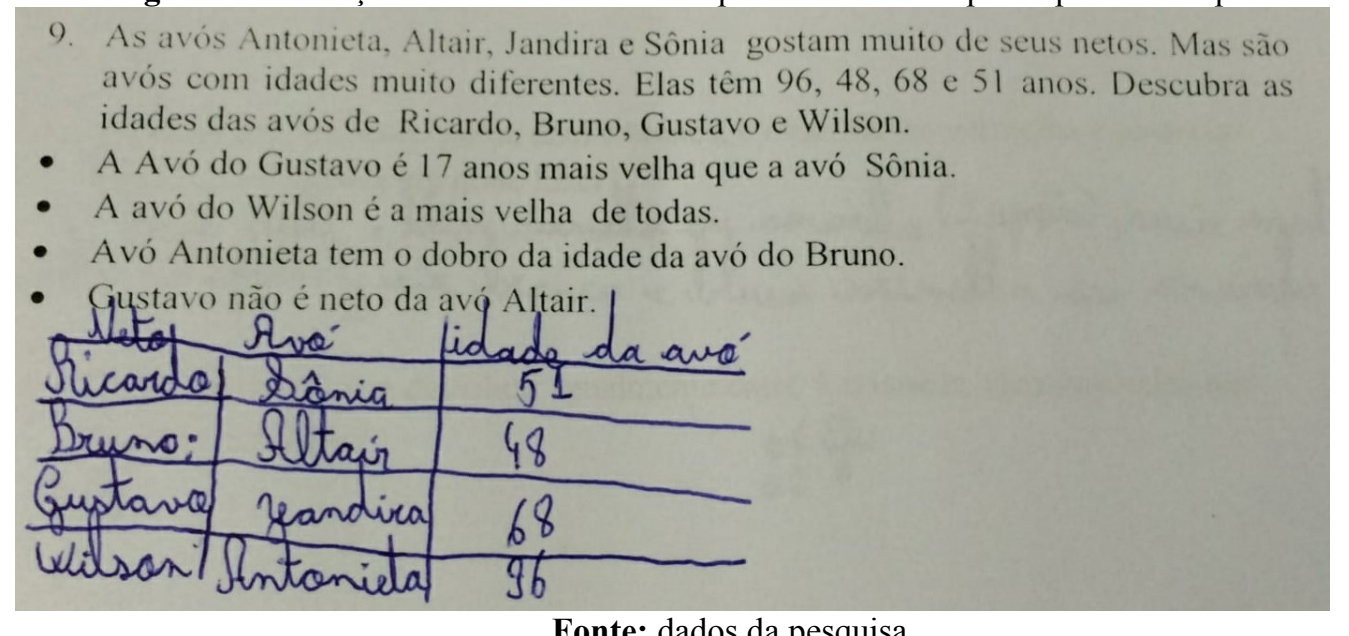

Fonte: dados da pesquisa.

A situação-problema de número dez, que encerra a lista de atividades propostas, contempla o conteúdo de estatística ou tratamento da informação. Requer habilidade aditiva baseada na leitura, na interpretação de gráficos, após a observação, fazendo uso da comparação e do pensamento de síntese na formalização de uma pergunta. Apresentou um desempenho de cinquenta e nove por cento de positividade. Esse resultado traduz a importância de um trabalho relacionado à natureza da questão, usual nos meios de comunicação como jornais, revistas e outras publicações nos quais figuram tabelas e gráficos. Esses podem contribuir para outras leituras, como legenda e escalas, ao ter contato com gráficos e imagens, podendo ainda suscitar perguntas a respeito dos mesmos, como é o caso da atividade proposta aos participantes da pesquisa. É uma aprendizagem de ferramentas para possíveis pesquisas simples, mas que despertam a curiosidade para o conhecimento da realidade que os cerca, ou seja, do seu entorno vivencial. A Figura 10 apresenta um exemplo de resolução correta de um estudante participante do experimento. 
Figura 10: resolução correta da atividade 10, realizada por um estudante participante do experimento.

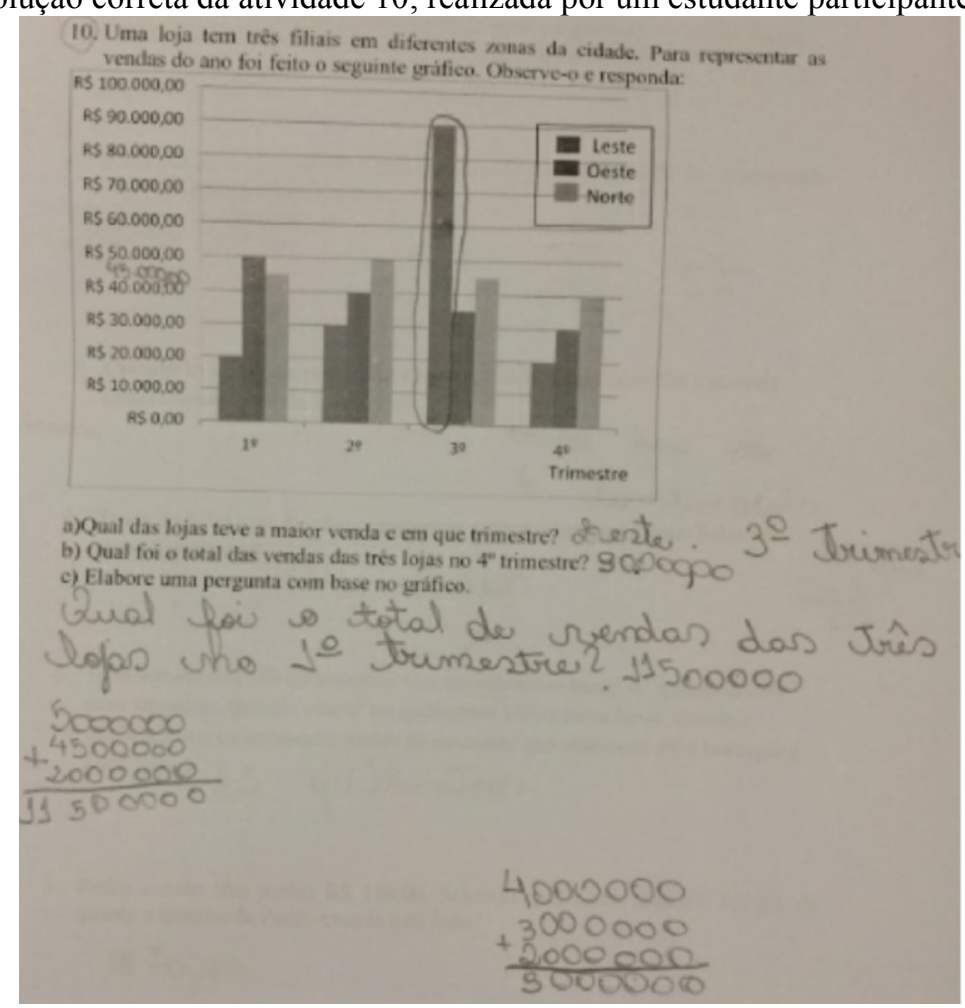

Fonte: dados da pesquisa.

\section{Considerações Finais}

O estudo proporcionou uma experiência positiva de integração entre professores/pesquisadores/Universidade/Secretaria Municipal de Educação de Canoas/RS, permitindo que os professores participantes do grupo analisassem as respostas e o desempenho dos seus estudantes, conhecendo os aspectos que necessitam de reforço e os que os estudantes dominavam.

A leitura e reflexão, no grupo de formação continuada, sobre os aspectos que compõem o currículo de Matemática para o sexto ano do Ensino Fundamental possibilitou uma definição de metodologias para ests ano escolar, entre essas, a resolução de problemas matemáticos no conjunto dos Números Naturais.

Também possibilitou que os professores refletissem sobre o ensino e aprendizagem desse processo, evidenciando que é interessante questionar, ao escolher uma atividade para trabalhar com os estudantes: Qual o objetivo dessa atividade? Que competência(s) o aluno irá desenvolver? Que habilidades são requeridas? Qual o sentido da atividade? O aluno domina o significado da terminologia? A atividade está associada ao seu meio ou a uma realidade mais ampla? 
Nesse sentido, a aplicação e análise dos resultados encontrados possibilitaram visualizar as carências e acertos dos estudantes, fazendo-os perceber a complexidade do tema ao estudá-lo, pois os autores referidos recomendam que o problema proposto ao aluno seja planejado com adequação aos seus conhecimentos prévios e compreensão vocabular. É preciso oferecer aos alunos o exercício de elaboração de planos de ação, a execução desses planos, a testagem de suas hipóteses e a validação das soluções encontradas.

A análise dos resultados da solução de problemas com Números Naturais, por alunos do sexto ano do Ensino Fundamental, revelou um lastro comum de desempenho em sessenta por cento das questões propostas, com mais de cinquenta por cento de acertos, obtendo-se sucesso nas questões envolvendo temas veiculados na mídia e desenvoltura no cálculo das operações simples. Entretanto, apontou dificuldades de compreensão e resolução das expressões vocabulares e na interpretação do contexto, descrição restrita da solução e a não verificação da mesma. Indicou, ainda, pequenos ensaios em relação ao pensamento lógico e combinatório.

Salienta-se que a média de acertos de 5,46 não pode ser considerada insatisfatória, porém, levanta debilidades em relação às turmas 3B e 4B.

As questões 1, 7 e 8 foram as questões resolvidas corretamente por mais de $80 \%$ dos 150 estudantes, apontando que os mesmos desenvolveram a habilidade de cálculo com o algoritmo da subtração e multiplicação com Números Naturais, bem como a competência da leitura e interpretação das questões fáceis.

As questões 2 e 6, consideradas difíceis, evidenciaram um percentual de acertos menor de $30 \%$, sinalizando dificuldades no conceito de excesso, dobro/metade e inversão ao interpretar/analisar situações na aplicação do cálculo de subtração e multiplicação.

O percentual de acertos, nas questões 3 e 9 (dificuldade média e difícil, respectivamente), foi pouco superior a 30\%, envolvendo o pensamento lógico e combinatório, próprio do estágio formal. Apesar dos resultados, é um indicador significativo e sinaliza a aplicação de esquemas e levantamento de hipóteses.

Considerando as limitações deste estudo, sugere-se sua continuidade e recomendam-se algumas ações que visem ao desenvolvimento da competência interpretativa e o enriquecimento vocabular, possível numa proposta interdisciplinar que ofereça diferentes situações de aprendizagem para que os estudantes possam construir uma base conceitual e operativa essencial à solução de problemas nesse conjunto numérico. 
Salienta-se que, conhecer o nível de conhecimentos dos alunos e das dificuldades que apresentam auxilia na escolha das situações-problema a serem trabalhadas, bem como nos conteúdos que devem ser reforçados e nas habilidades que tais situações podem desenvolver, possibilitando o observar com sentido, competência docente salientada por Llinares (2012).

\section{Referências}

CARVALHO, Mercedes. Problemas? Mas que problemas?!: estratégias de resolução de problemas matemáticos em sala de aula. 4. ed. Petrópolis, RJ: Vozes, 2010.

CORSO, Leonor Norma; MENZA, Ana Rosa La, La Matemática: del conflito al diálogo. Buenos Aires: Aique, 1999.

CRUZ, Carlos Henrique Carrilho. Competências e habilidades: da proposta à prática. 3. ed. São Paulo: Loyola, 2002.

CURY, Helena Noronha. Análise de erros: o que podemos aprender com as respostas dos alunos. Belo Horizonte: Autêntica, 2007.

DANTE, Luiz Roberto. Didática da resolução de problemas de Matemática. São Paulo: Ática, 1989.

DANTE, Luiz Roberto. Tudo é Matemática. São Paulo: Ática, 3 ed., 2009.

DUHALDE, María Helena; CUBERES, María Teresa González. Encontros iniciais com a Matemática: contribuições à educação infantil. Porto Alegre: Artes Médicas, 1998.

FERREIRA, Aurélio Buarque de Holanda. Aurélio: dicionário da língua portuguesa. $2^{\mathrm{a}}$ ed. Curitiba: Positivo, 2008.

GOULART, Iris Barbosa. Experiências básicas para utilização pelo professor. 11. ed. Petrópolis, Rio de Janeiro: Vozes, 1996.

GROENWALD, Claudia Lisete Oliveira. A metodologia resolução de problemas no ensino da Matemática. Artigo apresentado ao grupo de estudos. Canoas, RS: ULBRA, 2014.

KRULIK, Stephen; REYS, Robert E. (orgs.). A resolução de problemas na Matemática escolar. São Paulo: Atual, 1997.

LLINARES, Salvador. Construcción de conocimiento y desarollo de una mirada profesional para la práctica de enseñar matemáticas en entornos em linea. In: Avances de investigación en Educación Matemática. Espanha: Universidad de Alicante, v. 2, p. 53-70, 2012.

MACEDO, Lino de. Ensaios pedagógicos: como construir uma escola para todos? Porto Alegre: Artmed, 2005. 
NCTM. Principles to actions: ensuring mathematical sucess for all. Reston: National Council of Teachers of Mathematics, 2014.

NUNES, Karina Sales (et al). Inovando o currículo de Matemática através da incorporação das tecnologias da informação e comunicação - Ambiente de investigação com o tema Números Decimais. 2012. Disponível em: http://www.conferencias.ulbra.br/index.php/sic/xviii/paper/view/36. Acesso em 12 de jun de 2013.

PERRENOUD, Philippe. Construir as competências desde a escola. Porto Alegre: Artes Médicas Sul, 1999.

PIAGET, Jean. Psicologia da Inteligência. Rio de Janeiro: Zanar, 1977.

PÓLYA, George. A arte de resolver problemas: um novo aspecto do método matemático. Rio de Janeiro; Interciência, 2006.

SANCHEZ HUETE, Juan Carlos; FERNÁNDEZ BRAVO, José A. O ensino da matemática: fundamentos teóricos e bases psicopedagógicas. Porto Alegre: Artmed, 2006.

VILA, Antoni; CALLEJO, María Luz. Matemática para aprender a pensar: o papel das crenças na resolução de problemas. Porto Alegre: Artmed, 2006.

VILLELLA, José. Piedra Libre para la Matemática! Buenos Aires: Copyright, 1998. 